\title{
THE WORLD FLORA ONLINE, TARGET 1 OF THE GLOBAL STRATEGY FOR PLANT CONSERVATION, AND THE SPECIES PLANTARUM PROGRAMME: FLORA OF THE WORLD: COMPATIBLE CONCEPTS OR MUTUALLY EXCLUSIVE MANDATES? ${ }^{1}$ \\ Gideon F. Smith, ${ }^{2,3 *}$ Ronell R. Klopper, ${ }^{4,5}$ Peter Wyse Jackson, ${ }^{6}$ and Neil R. Crouch ${ }^{7,8}$
}

\begin{abstract}
The Species Plantarum Programme: Flora of the World (SPPFW) has been in existence for slightly more than two decades and during this time published basic taxonomic information for just over 1000 species, in 11 families. While an admirable initiative, at this pace it will take about 350 years to reach completion. At the 10th Conference of the Parties of the Convention on Biological Diversity (CBD), which was held in Nagoya, Japan, in October 2010, the Global Strategy for Plant Conservation (GSPC) was updated for the period up to 2020 (the first phase of the GSPC had been adopted in 2002). The first target of the Strategy aims to produce an online flora for all known plants of the world by 2020 , in about three years therefore. Governments that are parties to the $\mathrm{CBD}$ are due to report over the next few years on progress with achieving all of the 16 GSPC targets, including this challenging first target. While many individual countries have initiatives to prepare online digital floras of their own territory, it is recognized that the achievement of the World Flora target relies on the achievement of an international initiative, rather than having e-floras for each country. For that reason, in 2012 an international project was launched, which was welcomed by the CBD, to take forward this initiative. A World Flora Online (WFO) Consortium was subsequently established, now including 38 organizations and institutions worldwide, to take forward the achievement of this target. Although the SPPFW and WFO may be deemed to have similar objectives, the timeframe available to produce e-floras for countries that are parties to the CBD, and by implication for the world, will mean that conducting original monographic work toward refining and improving existing classifications will in many instances have to be either curtailed or brought to a swift conclusion. Without the necessary global support and funding, the slow progress of the SPPFW has clearly illustrated that producing a WFO is a very ambitious target to reach in less than a decade. Governments, plant taxonomists, botanical institutions, funding agencies, global initiatives, and stakeholders have not pooled resources to make a revision-driven World Flora — the SPPFW - a reality. Target 1 of the 2020 GSPC will, of necessity not be met through exclusively original work, but instead will need to rely on the synthesis of existing information, while identifying and attempting to fill significant taxonomic and geographical gaps. The implications for the SPPFW, as countries work toward achieving Target 1 of the GSPC, are discussed.

Key words: Flora, e-flora, e-taxonomy, Global Strategy for Plant Conservation, Species Plantarum Programme: Flora of the
\end{abstract} World, taxonomy, World Flora Online

Although the idea of initiating a modern World Flora was first mooted in the late $1980 \mathrm{~s}$, just over 25 years ago, the Species Plantarum Programme: Flora of the World (SPPFW) has now been formally in existence for some 23 years. Its first Steering Committee meeting took place in 1994 in Madrid (Smith, 1996). Subsequent meetings were held at ca. 18-month intervals in San Francisco (second meeting; Smith, 1997, 1998), Cape Town (third meeting; Smith, 1999a, 1999b), Průhonice, Czech Republic (fourth meeting; Smith, 2000), Sydney (fifth meeting; Smith, 2002), Paris (2003, sixth meeting), Panama (2004, seventh meeting), Vienna (eighth meeting;

\footnotetext{
1 Anonymous referees are thanked for their collegial contributions.

2 Department of Botany, P.O. Box 77000, Nelson Mandela University, Port Elizabeth, 6031 South Africa.

3 Centre for Functional Ecology, Departamento de Ciências da Vida, Universidade de Coimbra, 3001-455 Coimbra, Portugal.

4 Biosystematics Research and Biodiversity Collections Division, South African National Biodiversity Institute, Private Bag X101, Pretoria, 0001 South Africa.

${ }^{5}$ H.G.W.J. Schweickerdt Herbarium, Department of Plant Science, University of Pretoria, Pretoria, 0002 South Africa.

${ }^{6}$ Missouri Botanical Garden, P.O. Box 299, St. Louis, Missouri 63166-0299, U.S.A.

${ }^{7}$ Biodiversity Research, Assessment and Monitoring, South African National Biodiversity Institute, P.O. Box 52099, Berea Road, 4007 South Africa.

${ }^{8}$ School of Chemistry and Physics, University of KwaZulu-Natal, Durban, 4041 South Africa.

* Author for correspondence: smithgideon1@gmail.com.

doi: $10.3417 / \mathrm{D}-17-00004 \mathrm{~A}$
} 
Smith, 2005), Royal Botanic Gardens, Kew (2006, ninth meeting), and Beaufort, North Carolina (2008, 10th meeting). Most recently, to coincide with the XVIIIth International Botanical Congress (IBC), the 11th SPPFW meeting was held in Melbourne, Australia, during July 2011. The grandiose aims of this admirable global thrust were, and remain, to provide in concise format and with standardized fields, basic taxonomic information on the vascular plants of the world, including names, bibliographies, types, keys, descriptions, geography, and ecology, and to publish these data in both hard copy and electronic formats (Brummitt et al., 2001).

The sheer magnitude of this global enterprise requires the comprehensive commitment of the world's taxonomic fraternity, and by implication, of the leading botanical institutions that employ them. However, with the exception of several significant in-kind contributions received to date, such as that of the Australian Biological Resources Study (ABRS) and the Conservatoire et Jardin botaniques de la Ville de Genève in Switzerland (CJB), both of which provided editing facilities for the first several volumes in the series, and some financial support from the Bergius Foundation in Stockholm, Sweden, the SPPFW has been unable to attract the major financial support that it requires and deserves. This lack of necessary resources has hampered the progress of the Programme, particularly in that it has been unable to commission the completion of floristic revisions that can be published in the SPPFW series. Therefore, progress on the Flora has thus far been through the compilation and publication of comparatively small family accounts, and a few significant ones (e.g., see Kirschner, 2002, on the Juncaceae, and Prance \& Sothers, 2003, on the Chrysobalanaceae). Obtaining major global-scale treatments of flagship families has proven to be elusive.

At all recent meetings of the Steering Committee of the SPPFW, the Committee recognized the alarmingly slow progress that has been made with achieving its aims and decided to broaden and intensify its efforts to attract major donor and science council funding by adopting an approach that will embrace the electronic ether more effectively as far as both the generation and dissemination of revisions are concerned. As one example of this commitment, the Committee reconfirmed its earlier decision to advocate the use of the Botanical Records and Herbarium Management System (BRAHMS) as an input facility for the generation of online revisions and monographs. This system is currently widely in use across the world, including by a scientific consortium that will provide a treatment of the economically important genus Solanum L., which includes about 1700 species (<http://solanaceaesource.org/>). The possibility of expanding to a global scale the three components of the Flora Iberica internet facility, namely (1) descriptive Flora information, (2) specimen-based distribution records and maps, and (3) an interactive identification mechanism, was also investigated (<http://www.floraiberica.org/>).

A further development that came about at the 9th SPPFW Steering Committee meeting, held at the Royal Botanic Gardens, Kew, from 1 to 3 November 2006, was that the CJB, Genève, Switzerland, has committed itself to oversee the production and printing of the next few edited volumes in the hardcopy SPPFW publication series. These texts will be simultaneously posted on the internet.

In July 2011, the Steering Committee of the SPPFW met in Melbourne, Australia, 18 years after the concept of producing and disseminating uniform, global plant taxonomic treatments was first discussed in a modern context at the XVth IBC held in Yokohama, Japan, in 1993. Now, perhaps more so than ever, the Programme is in many ways at a crossroads. As it has taken over 20 years for the Programme to complete taxonomic treatments of just over 1000 species, one may reasonably question whether the SPPFW remains a viable option worth pursuing. Of course the idea is a noble one, but in lacking resources, some may argue that this endeavor is clearly proving to be too slow going to advocate as a major opportunity and unifying force in international taxonomic work. In this regard, securing committed project funding remains problematic. The generation of floras, as derivatives of sound monographic work, remains as important now as when Linnaeus classified the plants (and animals and minerals, for that matter) at his disposal some 300 years ago. As taxonomists collaboratively work out relationships among species and generate phylogenies, not having information-rich floras available for a wide range of end-users is highly alarming. Downstream users of floras as taxonomic outputs, e.g., conservation scientists, agronomists, weed scientists, ethnobotanists, invasions biologists, and many more, are concerned about the compounding effects (e.g., see Pyšek et al., 2013). When governments, decision- and policymakers, and conservation practitioners are working to conserve plant diversity in so many countries, the lack of comprehensive and authoritative floras to provide the baseline data they need for their regions is all too often a significant hindrance to achieving effective biodiversity conservation. The SPPFW has a robust steering and management structure that is able to oversee the execution of a taxonomic program of global significance and proportions. The management structure has stood the test of time-for over two decades-over which period it has not only survived but become firmly established. Although having the capacity to facilitate the production and dissemination of sound taxonomies, this committee has been hamstrung by underfunding. 
In terms of buy-in into, and support by, the international botanical community for the SPPFW, at the closing meeting of the IBC held in Vienna on 23 July 2005 , this group supported and resolved with an overwhelming majority:

\section{Resolution \#4 [Plant Biodiversity]}

\section{"We, the delegates of the XVII International Botanical} Congress:

Recognize that plants create the ecological habitat for all terrestrial organisms, and that their management and conservation depend on a good understanding of their taxonomy;

Lament that we still do not have an adequate taxonomic account of the world's flora and that for some groups and geographic areas we do not even have preliminary accounts;

Commend the admirable efforts of Target 1 of the Global Strategy for Plant Conservation to produce a working checklist of the flora of the world by 2010;

Encourage the efforts of the major regional floras and of the Species Plantarum Programme (SPP) to continue to enrich and expand the world checklist by rapidly generating and disseminating treatments of the taxonomy of the world's flora.

We urge the SPP Steering Committee and the governing boards of the regional floras to increase their efforts to obtain international collaboration and to gather adequate national and international funding to accomplish this important work that is vital for the conservation and sustainable use of all plant resources" (Resolutions Committee of the XVIIth International Botanical Congress, 2005).

Significantly, the lengthier "Resolution \#5 [Plant Conservation]" that dealt with the Global Strategy for Plant Conservation (GSPC) confirmed this resolution as it included the following paragraph: “...to support efforts to ensure that information on plants vital for their conservation is made widely accessible, through the Internet and by other means, including the urgent completion of a widely accessible working list of known plant species, as a step towards a complete world Flora." Indeed, the GSPC is providing additional impetus to the efforts of taxonomists to show the significance of a World Flora (Smith \& Smith, 2006).

At the final meeting of the XVIIIth IBC, held in Melbourne, Australia, on 30 July 2011, the following resolution was adopted in support of the GSPC and its 2020 targets.

\section{Resolution \#1}

"We applaud the adoption of an updated Global Strategy for Plant Conservation by the U.N. Convention on Biological Diversity at its 10th meeting of its Conference of the Parties held in Nagoya, Japan, in October, 2010; and call for:

- governments and inter-governmental bodies to recognize the achievements of the Global Strategy for Plant Conservation (GSPC) and the urgent priority of its 2020 targets, by incorporating and mainstreaming its objectives into all relevant plans, policies, and programs, including economic development policies, and programs to achieve sustainable development and poverty alleviation, as well as into national biodiversity strategies and action plans;

- botanical, environmental, and conservation organizations and institutions worldwide to redouble their efforts to achieve the objectives of the GSPC by 2020 ;

- governments, inter-governmental agencies, donors, and other bodies to provide new resources to support plant conservation actions and to help build capacity for the management and conservation of plant resources worldwide;

- botanical institutions worldwide to collaborate to achieve a comprehensive and authoritative "online flora of all known plants" by 2020;

- scientists worldwide to contribute toward assessing the conservation status of plant species worldwide, giving highest priority to the most threatened plants and habitats, considering the projected impacts of global climate change, and utilizing all available methods;

- acknowledgement of the principle and fundamental importance of sharing knowledge and other benefits derived from scientific research with the countries and institutions from which genetic resources have been obtained" (Resolutions Committee of the XVIIIth International Botanical Congress, 2011).

Furthermore, in "Resolution \#3" of the XVIIIth IBC, governments and policymakers are called on, amongst other things, to "actively develop floras and detailed accounts of the plants of all regions, which provide the basic information used to protect plants, understand their functions, and utilize them sustainably" and to "provide for the wide dissemination of information throughout the world by facilitating universal access to the increasingly powerful tools of electronic information management and communication" (Resolutions Committee of the XVIIIth International Botanical Congress, 2011).

\section{Enter the Global Strategy for Plant Conservation}

The GSPC was unanimously adopted and approved at the 6th meeting of the Conference of Parties (COP) to the Convention on Biological Diversity (CBD) held in The Hague in April 2002 (UNEP, 2002). Its initial objects 
were the achievement of 16 targets by 2010 . Its ultimate and long-term objective is to halt the current and continuing loss of plant diversity (Wyse Jackson \& Kennedy, 2009). In this sense the GSPC was seen as providing a framework to facilitate accord between existing initiatives aimed at plant conservation, to identify gaps where new initiatives were required, and to promote mobilization of the necessary resources (Crouch \& Smith, 2011). Target 1 of the GSPC was "a widely accessible working list of all known plant species, as a step towards a complete world Flora." This preliminary checklist was achieved with the launch of "The Plant List" (<http://www.theplantlist.org/>). The Plant List is clearly a work in progress that aims to be a "best effort" list, to demonstrate progress and to stimulate further work. The Plant List includes 1,064,035 scientific plant names at the species rank. Of these, 350,699 (33.0\%) are accepted species names. A total of 470,624 (44.2\%) names included are synonyms and 242,712 (22.8\%) are unresolved. It currently contains contributions from the Royal Botanic Gardens, Kew, the Missouri Botanical Garden, Global Compositae Checklist, the International Legume Database and Information Service (ILDIS), the Royal Botanic Garden, Edinburgh, the South African National Botanical Institute, and the CJB, Genève, Switzerland.

In 2011 the CBD developed and adopted the Strategic Plan for Biodiversity and its related Aichi Targets to be achieved by 2020 . This also provided an opportunity for the CBD Parties to update the GSPC and its targets toward 2020, recognized as an important contribution to the CBD's Strategic Plan. Therefore at the 10th COP of the CBD, held in Nagoya, Japan, in October 2010, an updated GSPC was adopted as a cross-cutting initiative (UNEP, 2010). A revised GSPC Target 1 was included in the 2011-2020 GSPC, going beyond the target of having a preliminary checklist of the World Flora in the first phase of the GSPC, toward the achievement of an ambitious "online flora of all known plants" by 2020 (<https://www.cbd.int/gspc/strategy. shtml $>$ ): (1) to add descriptive and other flora-style information to the checklist and (2) to disseminate such information electronically.

As a result, the first target of the Strategy now aims to produce an electronic flora for all known plants of the world by 2020 — now in less than four years (Crouch et al., 2013; Victor et al., 2013b; Wyse Jackson \& Miller, 2015). In this regard, item no. 13 of the Final Declaration of the international conference "Botanists of the twenty-first century: roles, challenges and opportunities" (Rakotoarisoa et al., 2016: 250), called on the community of botanists and plant scientists in general, and on the organizations for which they work, to "increase their efforts to achieve the objectives and targets of the GSPC, especially those primarily undertaken by botanists, including the successful completion of a World Flora Online by 2020 to provide an essential baseline of knowledge about plants of the world" (<http://unesdoc.unesco.org/images/0024/002437/ 243791 m.pdf $>$ ).

It is proposed that this be achieved by adding, inter alia, more complete synonymy and geographic distributions to the country level to the 2010 world plant checklist, The Plant List, which, from its inception, was understood to be a work in progress. For example, version 1.1 (dated September 2013) has replaced version 1.0 (see <http://www.theplantlist.org/>). The Plant List was used as the initial input for the construction of the nomenclatural backbone for the World Flora Online (WFO), modified and updated as more taxonomic information and expertise becomes available to improve it. Descriptions will also be added, generally derived from those previously included in various floras and monographic accounts. The additional information can be obtained in national and other floras and (annotated) checklists where these exist, and also in part from international initiatives (IUCN, 2010), including the SPPFW. The targets of the GSPC are global-level targets, and although progress can be made at the country or regional level, these necessarily require consolidation to form global-level outputs. In this respect the aims of Target 1 of the GSPC and those of the SPPFW are complimentary and compatible concepts.

\section{The Future of the Species Plantarum Programme: FLORA OF THE WORLD}

The ability of the SPPFW to coordinate and scientifically support international revisionary and monographic activities has already been clearly demonstrated. Such taxonomic work, which is core to the SPPFW and implicit in the optimal delivery of Target 1 for the 2020 GSPC, should represent the collaboration of international institutions worldwide, as envisaged by the IBC. As initiatives are already well underway to coordinate the WFO, and with the support of resources invested in other, complementary revisionary and traditional flora work, it may be that the SPPFW would have a larger role to play post 2020, to inform the continued improvement of a WFO. The completion of some floras has been given new impetus given that these treatments will also be included in the WFO. For example, the Missouri Botanical Garden will contribute information to the WFO that results from more than 40 years of activity and will make continued efforts to complete floristic inventories of various parts of the world. This will include contributions from the Flora of North America, Flora Mesoamericana, Flora of the Venezuelan Guayana, Flora of China, the Madagascar Catalog (including the other islands of the southwestern Indian Ocean), and checklists of Ecuador, Peru, Bolivia, 
and the South American Southern Cone (Argentina, Chile, Paraguay, and Uruguay). In addition, raising funds to support ongoing taxonomic work has been facilitated given their projected ultimate adoption into the $\mathrm{WFO}$ as a needs- and timeline-driven thrust.

While delivery on the 2020 GSPC Target 1 at least to some degree focuses on data-capture into electronic formats, and synthesis of existing and new information where possible, curatorial and expansion activities on the content captured will benefit from the experienced perspective and formal training of taxonomists. In fact, the WFO is drawing heavily on the expertise of taxonomists, in particular to inform and improve the "taxonomic backbone" that is the successor of The Plant List. The compatibility and required cooperation between these two initiatives, The Plant List and the WFO, are of considerable importance as they are linked through the GSPC and not mutually exclusive stand-alone thrusts.

\section{ConcLusion}

As envisaged from its initiation, the WFO is being developed to be a free, open-access, online, web-based resource providing access to floristic data on a global scale, thereby enabling an overview of the known vascular plants and bryophytes of the world, particularly to support plant conservation objectives. To meet the target of producing the WFO by 2020, the web-based WFO facility will necessarily contain a majority of existing data derived from national and regional floras, as well as monographs and other resources. The WFO will, therefore, not be a critical, monographic revision of the world's plants and not necessarily provide vouchered distributional data as would be encountered in a more detailed local flora (WFO, 2013). Since, on the other hand, the SPPFW is essentially aimed at having fresh taxonomies and monographs done, there is a clear and fundamental difference between this Programme and the WFO. Of course, as the WFO e-production line becomes increasingly on-stream and absorbs content, gaps in taxonomic information and expertise will necessarily become clear. Such gaps exposed by the WFO will inform the setting of priorities for monographic treatments at global, regional, and country levels (e.g., see Victor \& Smith, 2011; Victor et al., 2013a, 2015a, 2015b). Justifiably, it could be asked whether an SPPFW-like project is required to deal with such gaps, up to and beyond 2020. Alternatively, and possibly more simply and effectively, institutions should be urged to incorporate treatments required into their corporate strategies and current and future work plans (Victor et al., 2016).

Ten years after the world celebrated the 300th birthday of Linnaeus in 2007, as part of whose legacy the world collectively inherited the prototype SPPFW, there remains wide recognition for the need for global plant taxonomies (Klopper et al., 2002). These should ideally be based on or, at worst, be informed by original research. To comprehensively achieve this within the space of less than four years before the WFO's 2020 deadline is not only unlikely but impossible. The challenge to have a global flora accessible electronically within this timeframe requires the innovative use and repackaging of existing taxonomic products and content. Given the near-global governmental support for the CBD, which has endorsed the GSPC targets, it is, therefore, likely that such consolidation and digitization of existing data in most instances will have to be the approach for the achievement of a WFO, while at the same time undertaking and supporting their own national or regional e-flora projects. In contrast, the SPPFW offers consistent, global treatments based on sound, expert-driven taxonomy and effective, highquality editing -in a way, therefore, "ultimate" treatments (or as "ultimate" as a taxonomic treatment can ever profess and hope to be). But somehow the Programme never attracted the interest, funding, and support it so richly deserved.

Naturally one wonders how much progress would have been made with producing an SPPFW by the time Linnaeus' 400th birthday is celebrated. In the past, taxonomists have often failed to obtain the sympathies of politicians and funders and to impress on decisionmakers the importance of attracting resources that support foundational research that underpins all other biological research: taxonomy. Why are we not managing to do so more comprehensively, one inevitably has to ask, given the importance of this task? Perhaps the way that the WFO is linked to specific outcomes for plant conservation, education, and sustainable use, as incorporated in GSPC targets, has now helped it to gain wider traction, in some cases even attracting significant government and other funding.

Ultimately, the success of the WFO will depend to a large degree on significant community participation; this will in turn require dependable and regular communication from the WFO and editing tools that can be easily adopted by prospective content providers, such as taxon specialists. Similarly, to ensure the longevity of the WFO, active community involvement will largely determine the long sustainability of the resource. Once WFO participants have developed a sense of ownership of the thrust, keeping its content current will become significantly easier.

The WFO has been a stimulus for original biosystematics research, if for no other reason, purely because there is a WFO 2020 deadline looming large on the horizon. For example, in Brazil, the Brazilian Council for Research in Science and Technology, the Jardim Botânico do Rio de Janeiro (JBRJ), and a range of 
Brazil-based sponsors and other organizations are cooperating to deliver the REFLORA program, designed to facilitate the creation of an online "Flora do Brasil Digital," Brazil's response to GSPC Target 1 (Wyse Jackson \& Miller, 2015). In 2010 to 2011, the Brazilian government established the multilateral REFLORA program which is aimed at disseminating images and information about Brazilian plants, including specimens, that are deposited mainly in overseas herbaria through an online facility, the REFLORA Virtual Herbarium. To further support and strengthen this fast-emerging global taxonomic thrust, greater collaboration between the SPPFW and WFO going forward must be encouraged, so that the SPPFW, which will also benefit from a greater community-wide sense of ownership, becomes a source of new, exemplary taxonomic information, and in turn can benefit from the impetus and profile with governments that has been gained for plant taxonomy generally through the WFO. The WFO will certainly remain beyond 2020 , and it is intended that it will continue to incorporate the best up-to-date accounts and taxonomic opinion, especially if there is community buy-in. Over the past decade, the world has seen an unprecedented electronic release of primary resources required for taxonomy and systematics through previously only imagined information technology advances (e.g., the Global Plants Initiative; see Smith \& Figueiredo, 2014, Biodiversity Heritage Library, and other, similar initiatives). These collectively present the potential for the unprecedented facilitation of revisionary studies and for capturing the outputs as vastly enriched WFO content.

\section{Literature Cited}

Brummitt, R. K., S. Castroviejo, A. C. Chikuni, A. Orchard, G. F. Smith \& W. L. Wagner. 2001. The Species Plantarum Project, an international collaborative initiative for higher plant taxonomy. Taxon 50: 1217-1230.

Crouch, N. R. \& G. F. Smith. 2011. Informing and influencing the interface between biodiversity science and biodiversity policy in South Africa. Bot. J. Linn. Soc. 166: 301-309.

Crouch, N. R., G. F. Smith \& E. Figueiredo. 2013. From checklists to an e-Flora for southern Africa: Past experiences and future prospects for meeting Target 1 of the 2020 Global Strategy for Plant Conservation. Ann. Missouri Bot. Gard. 99: 153-160.

IUCN. 2010. The Global Strategy for Plant Conservation (GSPC) 2011-2020...and what it means for you. <http:// cmsdata.iucn.org/downloads/guide_gspc__english.pdf $>$, accessed 7 March 2017.

Kirschner, J. (comp.). 2002. Juncaceae 1, 2 \& 3. Species Plantarum: Flora of the World, Parts 6-8. Australian Biological Resources Study, Canberra.

Klopper, R. R., G. F. Smith \& A. C. Chikuni. 2002. The Global Taxonomy Initiative in Africa. Taxon 51: 159-165.

Prance, G. T. \& C. A. Sothers. 2003. Chrysobalanaceae $1 \& 2$. Species Plantarum: Flora of the World, Parts 9-10. Australian Biological Resources Study, Canberra.

Pyšek, P., P. E. Hulme, L. A. Meyerson, G. F. Smith, J. S. Boatwright, N. R. Crouch, E. Figueiredo, et al. 2013. Hitting the right target: Taxonomic challenges for, and of, plant invasions. AoB Plants 5: plt042; doi: 10.1093/aobpla/042.

Rakotoarisoa, N. R., S. Blackmore \& B. Riera (editors). 2016. Final Declaration of the International Conference Botanists of the twenty-first century: Roles, challenges and opportunities. Pp. 249-252 in Botanists of the Twenty-first Century: Roles, Challenges and Opportunities. Based on the Proceedings of UNESCO International Conference, 22-25 September 2014. United Nations Educational, Scientific and Cultural Organisation, Paris. <http://unesdoc.unesco.org/ images/0024/002437/243791m.pdf $>$, accessed 13 April 2017.

Resolutions Committee of the XVIIth International Botanical Congress. 2005. Resolutions from IBC 2005 Vienna. Pp. 1-4. Unpublished list of resolutions presented at the closing session, Vienna.

Resolutions Committee of the XVIIIth International Botanical Congress. 2011. Resolutions from IBC 2011 Melbourne. Pp. 1-3. Unpublished list of resolutions presented at the closing session, Melbourne.

Smith, G. F. 1996. The Species Plantarum Project-A world flora in the making. S. African J. Sci. 92: 171-172.

Smith, G. F. 1997. Progress with the Species Plantarum Project. S. African J. Sci. 93: 387-388.

Smith, G. F. 1998. Species Plantarum: Flora of the World. Can southern African systematists contribute? SABONET News 3: 29-31.

Smith, G. F. 1999a. Documenting plant diversity on a global scale: Recent progress with the Species Plantarum: Flora of the World Project. S. African J. Sci. 95: 55-56.

Smith, G. F. 1999b. Recent progress with the Species Plantarum: Flora of the World Project. SABONET News 4: 52-54.

Smith, G. F. 2000. Further developments in the Species Plantarum: Flora of the World Project. S. African J. Sci. 96: 482-483.

Smith, G. F. 2002. The Species Plantarum Project: Flora of the World moves ahead. S. African J. Sci. 98: 28.

Smith, G. F. 2005. Progress on the Species Plantarum Programme-Flora of the World at the International Botanical Congress in Vienna. S. African J. Sci. 102: 3. Smith, G. F. \& E. Figueiredo. 2014. The Global Plants Initiative: Where it all started. Taxon 63: 707-709.

Smith, G. F. \& T. J. Smith. 2006. Objective 1. Understanding and documenting plant diversity. Target 1 . A widely accessible working list of known plant species, as a step towards a complete world Flora. Catalogues of South African plant life: Documenting diversity for the benefit of all. Pp. 12-14 in C. K. Willis (editor), Conserving South Africa's Plants. A South African Response to the Global Strategy for Plant Conservation. SANBI Biodiversity Series 1: South African National Biodiversity Institute, Pretoria.

UNEP. 2002. Global Strategy for Plant Conservation. COP Decision VI/9. CBD Secretariat. <https://www.cbd.int/ decision/cop/?id=7183>, accessed 7 March 2017.

UNEP. 2010. Consolidated update of the Global Strategy for Plant Conservation 2011-2020. COP 10 Decision X/17. CBD Secretariat. <https://www.cbd.int/doc/decisions/cop10/cop-10-dec-17-en.pdf>, accessed 7 March 2017.

Victor, J. E. \& G. F. Smith. 2011. The conservation imperative and setting plant taxonomic research priorities in South Africa. Biodivers. \& Conservation 20: 1501-1505.

Victor, J. E., M. Hamer \& G. F. Smith. 2013a. A biosystematics research strategy for the algae, animals, bacteria and archaea, fungi and plants of South Africa 2013-2018. South African National Biodiversity Institute, Pretoria.

Victor, J. E., G. F. Smith, N. J. Turland, M. le Roux, A. Paton, E. Figueiredo, N. R. Crouch, et al. 2013b. Creating an online 
world Flora by 2020: A perspective from South Africa. Biodivers. \& Conservation 23(1): 251-263.

Victor, J. E., G. F. Smith \& A. E. van Wyk. 2015a. A method for establishing taxonomic research priorities in a megadiverse country. Phytotaxa 203: 55-62.

Victor, J. E., G. F. Smith \& A. E. van Wyk. 2015b. Strategy for plant taxonomic research in South Africa 2015-2020. SANBI Biodiversity Series 26. South African National Biodiversity Institute, Pretoria.

Victor, J. E., G. F. Smith \& A. E. van Wyk. 2016. Strategy for biosystematics research in South Africa: Overview of the plant systematics component. Pp. 201-206 in N. R. Rakotoarisoa, S. Blackmore \& B. Riera (editors), Botanists of the Twenty-first Century: Roles, Challenges and Opportunities. Based on the proceedings of UNESCO international conference, 22-25
September 2014. United Nations Educational, Scientific and Cultural Organisation, Paris. <http://unesdoc.unesco. org/images/0024/002437/243791m.pdf $>$, accessed 7 March 2017.

World Flora Online (WFO). 2013. World Flora OnlineTechnical Report on use cases. Version 6. 13 November 2013. Unpublished report presented at the World Flora Online Council meeting held at the Royal Botanic Garden Edinburgh, Edinburgh, 14-15 November 2013. 7 pp.

Wyse Jackson, P. \& K. Kennedy. 2009. The Global Strategy for Plant Conservation: A challenge and opportunity for the international community. Trends Pl. Sci. 14: 578-580.

Wyse Jackson, P. \& J. S. Miller. 2015. Developing a World Flora Online-A 2020 challenge to the world's botanists from the international community. Rodriguésia 66: 939-946. 